\title{
In vitro assessment of antibacterial activity from Lactobacillus spp. strains against virulent Salmonella species isolated from slaughter animals in Benin
}

\author{
Alidehou Jerrold Agbankpe ${ }^{1}$, Tamegnon Victorien Dougnon ${ }^{1}$, Roubaya Balarabe ${ }^{1}$, Esther Deguenon ${ }^{1}$ and \\ Lamine Baba-Moussa²
}

1. Research Unit in Applied Microbiology and Pharmacology of Natural Substances, Research Laboratory in Applied Biology, Polytechnic School of Abomey-Calavi, University of Abomey-Calavi, Cotonou, Benin; 2. Laboratory of Biology and Molecular Typing in Microbiology, Faculty of Science and Technology, University of Abomey-Calavi, Cotonou, Benin. Corresponding author: Alidehou Jerrold Agbankpe, e-mail: agbankpejerrold@yahoo.fr

Co-authors: TVD: victorien88@hotmail.com, RB: roubayabalarabe@gmail.com, ED: mixesther2009@yahoo.fr, LB: laminesaid@yahoo.fr

Received: 31-07-2019, Accepted: 08-11-2019, Published online: 13-12-2019

doi: www.doi.org/10.14202/vetworld.2019.1951-1958 How to cite this article: Agbankpe AJ, Dougnon TV, Balarabe R, Deguenon E, Baba-Moussa L (2019) In vitro assessment of antibacterial activity from Lactobacillus spp. strains against virulent Salmonella species isolated from slaughter animals in Benin, Veterinary World, 12(12): 1951-1958.

\begin{abstract}
Background and Aim: Salmonella spp. are among the world's leading foodborne pathogens, found naturally in the intestines of many animals. Lactic acid bacteria, mainly Lactobacillus, are a promising alternative to antibiotics for animal and human health. This study aimed to assess the in vitro antibacterial activity of Lactobacillus spp. strains against virulent Salmonella spp. isolated from slaughter animals in Benin.

Materials and Methods: Eleven samples of raw cow's milk, five samples of breast milk, and six infant stool samples were taken. From these samples, strains of Lactobacillus were isolated and identified. The probiotic potential of each of the identified strains was characterized, and finally in vitro antibacterial activity of these strains was evaluated against three virulent strains of Salmonella spp. and a reference strain of Salmonella Typhimurium ATCC 14028.

Results: Out of the 22 samples collected, 20 strains of Lactobacillus spp. were isolated and identified. These strains included Lactobacillus plantarum (30\%), Lactobacillus delbrueckii (25\%), Lactobacillus casei (25\%), Lactobacillus salivarius (15\%), and Lactobacillus acidophilus (05\%). Characterization of the probiotic potential of these strains showed that only 16 strains were resistant to $\mathrm{pH}=1.5$. Fourteen of them were able to withstand the simulated gastric juice ( $\mathrm{pH} 1.5+\mathrm{pepsin})$. The 14 probiotic strains showed very good antibacterial activity against virulent strains of Salmonella spp. with inhibition zone diameters ranging from $12.36 \pm 0.03 \mathrm{~mm}$ to $35.33 \pm 0.05 \mathrm{~mm}$ ( $\mathrm{R}$ values $>6 \mathrm{~mm}$ ).
\end{abstract}

Conclusion: From this study, Lactobacillus strains isolated from raw cow milk, breast milk, and infantile stool might be used as some valid candidates for probiotics. It also represents good alternatives for antibiotics in the fight against animal and human salmonellosis.

Keywords: antibacterial activity, Benin, Lactobacillus spp., probiotic, Salmonella spp.

\section{Introduction}

Salmonellosis, an infection caused by the bacteria called Salmonella, is one of the leading causes of foodborne illness in humans and animals. Although animals, such as pigs, chickens, and cattle, infected with Salmonella do not normally show symptoms, carcasses and meats are the main reservoirs of the pathogen [1]. In the United States and the European Union, outbreaks of salmonellosis have been reported each year. In the world and humans, there are approximately 93.8 million cases of salmonellosis causing approximately 155,000 deaths/year [2,3]. Minor salmonellosis (non-typhoid) causes 3.4 million

Copyright: Agbankpe, et al. Open Access. This article is distributed under the terms of the Creative Commons Attribution 4.0 International License (http://creativecommons.org/licenses/ by/4.0/), which permits unrestricted use, distribution, and reproduction in any medium, provided you give appropriate credit to the original author(s) and the source, provide a link to the Creative Commons license, and indicate if changes were made. The Creative Commons Public Domain Dedication waiver (http:// creativecommons.org/publicdomain/zero/1.0/) applies to the data made available in this article, unless otherwise stated. infections and 681,000 deaths worldwide. In Africa, non-typhoid Salmonella is a major cause of bacteremia, particularly in children and people with compromised immune functions [3]. Antibiotics are used for the prevention and treatment of infectious diseases. However, the appearance of antibiotic-resistant bacteria in humans and animals is linked to the widespread use of antibiotics in farmed animals [4].

The major public health problem caused by non-typhoid Salmonella was amplified by the emergence of multidrug-resistant strains [5]. It has been recognized that the emergence of antimicrobial resistance, particularly multidrug resistance to ampicillin, chloramphenicol, and cotrimoxazole, has complicated the treatment and management of salmonellosis [6]. Increased antibiotic usage is a key factor in the emergence of antibiotic-resistant pathogens. Thus, there is an urgent need to develop alternatives to antibiotics. The use of probiotics is then given great attention as an alternative to antibiotics [1]. Probiotics are widely studied and implemented in several applications such 
as the prevention of food poisoning or the treatment of certain gastrointestinal disorders [7]. Identified as an alternative treatment for Salmonella infections, probiotics are associated with fewer side effects and better safety. Several studies indicate that different Lactobacillus strains could inhibit the adhesion of Salmonella, thus reducing colonization and preventing infection $[7,8]$.

In the search for an alternative solution to the use of antibiotics in the treatment of Salmonellosis in Benin, the present study was initiated. It aims to assess in vitro antibacterial activity of Lactobacillus spp. strains against virulent Salmonella spp. isolated from slaughter animals in Benin.

\section{Materials and Methods}

\section{Ethical approval}

The manuscript does not contain clinical studies or patient data. The approval of the ethics committee was not required. However, samples were collected as per standard sample collection methods.

\section{Sampling}

Samples of raw cow's milk, breast milk, and infant feces were collected from cattle farms, nursing mothers, and healthy children (without sex distinction) aged $0-5$ years, respectively. For breast milk and infant stool samples, informed consent of nursing mothers and one of the parents was obtained before sampling. All samples were aseptically made in sterile Stomacher bags and/or sterile pots. Each sample was identified and placed in a cooler containing cold accumulators. These samples were immediately sent to Research Unit in Applied Microbiology and Pharmacology of natural substances, University of Abomey-Calavi, for analysis. The objective was to evaluate the probiotic potential and anti-Salmonella activity of Lactobacillus strains isolated from cow's milk samples. Hence, it was not necessary to evaluate the influence of external factors on the composition of the microbiome of cattle.

\section{Enrichment, isolation, and purification of Lactobacillus strains}

Five grams or $5 \mathrm{ml}$ of each sample were separately transferred aseptically into $45 \mathrm{ml}$ of Man, Rogosa and Sharpe (MRS) broth (M1164-500G, HIMEDIA, India) and incubated for $24-48 \mathrm{~h}$ at $37^{\circ} \mathrm{C}$ for the enrichment of Lactobacillus.

To isolate the Lactobacillus strains, ten-fold serial dilution $10^{-1}-10^{-5}$ was prepared from the pre-enriched broths. One milliliter of each dilution was inoculated on MRS agar w/low pH (M1927-500G, HIMEDIA, India) at the rate of three dishes by dilution. The Petri dishes were incubated anaerobically at $37^{\circ} \mathrm{C}$ for $24-72 \mathrm{~h}$.

To purify the Lactobacillus strains, several successive subcultures were carried out on MRS agar. Transplanting and resuspension were performed only for very distinct, homogeneous, and well-developed colonies. The purity of the strain was verified by macroscopic and microscopic examination. Isolated Lactobacillus strains were stored on MRS broth with $40 \%(\mathrm{v} / \mathrm{v})$ sterile glycerol $(99 \%)$ at $-20^{\circ} \mathrm{C}$.

\section{Identification of isolates}

The identification of species of Lactobacillus genus was based on the study of physiological characters (macroscopic and microscopic examination after Gram-staining, growth at different temperatures, and culture on hostile environments) and biochemical characters (catalase, indole, oxidase, mannitol mobility, Triple Sugar Iron [TSI] agar, and fermentation of sugars).

\section{Physiological characters}

Macroscopic and microscopic examination

The macroscopic examination consisted of describing the colonies obtained after culture on solid MRS medium of the bacterial strain during $48 \mathrm{~h}$ : According to pigmentation, contour, and aspect. After Gram-staining, microscopic examination allowed us to retain Gram-positive bacilli or coccobacilli.

\section{Growth at different temperatures}

A pure colony of each Lactobacillus isolate was emulsified into MRS broth and incubated at 15, 30, and $45^{\circ} \mathrm{C}$ for $48 \mathrm{~h}$. The results (growth by turbidity) were read after $48 \mathrm{~h}$ for the last two temperatures and for 4 days for the test at $15^{\circ} \mathrm{C}$. These tests allowed us to evaluate the ability of bacterial isolates to grow over a wide range of temperatures.

Culture on hostile environments

Adding 6.5 and $4 \%, \mathrm{NaCl}$ (Cooper, French, 1304C028A) in MRS broth prepared the high salt medium. The culture on saline medium was studied by inoculation of one colony of each Lactobacillus isolate; the incubation was carried out at $37^{\circ} \mathrm{C}$ for $48 \mathrm{~h}$ in anaerobiosis, any positive reaction results in the presence of turbidity. Hundred microliters of these broths obtained after $48 \mathrm{~h}$ were inoculated on MRS agar. Lactobacillus colonies obtained on MRS agar plates after anaerobic incubation at $37^{\circ} \mathrm{C}$ for $24 \mathrm{~h}$ were counted.

\section{Biochemical characters}

The isolated Lactobacillus strains were subjected to catalase (using $\mathrm{H}_{2} \mathrm{O}_{2}$ on glass slide), oxidase (using oxidase discs), and indole test.

\section{Study of fermental type and mobility test}

Homofermentative and heterofermentative tests were performed in TSI agar medium. A pure and young Lactobacillus colony was collected and seeded by streaks on the slope and by a deep puncture in the TSI (Sterile Screw Tube) agar. The tubes thus seeded will be incubated at $37^{\circ} \mathrm{C}$ for $48 \mathrm{~h}$ under anaerobic conditions. The development of a homofermentary species does not cause discontinuity in the medium. Moreover, the presence of bubbles in the 
culture medium reflects a $\mathrm{CO}_{2}$ release characteristic of heterofermentary species. Apart from the fermental type, TSI agar has also allowed us to read the fermentation of lactose and glucose.

Mannitol is a product for the reduction of D-mannose. It allows us to simultaneously researching the fermentation of mannitol and mobility. The isolates studied were inoculated into the mannitol medium, and incubated at $37^{\circ} \mathrm{C}$ under anaerobic conditions for $48 \mathrm{~h}$.

\section{Fermentation of sugars}

In addition to lactose, glucose, and mannitol, the fermentation of fructose, arabinose, maltose, galactose, and sucrose was studied. This sugar fermentation test was carried out on MRS plus phenol red medium free of meat extract and glucose with the addition of a $\mathrm{pH}$ indicator. We have tested the fermentation of various added sugars as the only carbon source in MRS red phenol.

The sugar solutions were prepared at $1 \%$ in sterilized distilled water by heating at $100^{\circ} \mathrm{C}$ for $30 \mathrm{~min}$. From the young cultures of the strains, a culture colony was put in a sterile hemolysis tube with physiological saline, and then two successive centrifugations (3000 rpm for $20 \mathrm{~min}$ ) were carried out to ensure a washing, in following $3 \mathrm{ml}$ of MRS plus phenol red were added to the pellet. On a microplate $10 \mu 1$ of different sugars were distributed in then, already containing $100 \mu \mathrm{l}$ of the bacterial suspension. An MRS broth control was performed. Finally, the microplates were incubated at $37^{\circ} \mathrm{C}$ for $24-48 \mathrm{~h}$. A positive result was a color shift [9].

\section{Assessment of in vitro probiotic abilities}

\section{Ability to survive in simulated gastric conditions}

To study the probiotic properties of identified Lactobacillus strains tests for tolerance to pepsin (simulated gastric juice) and low-pH (acid), following the protocol of Huang and Adams [10]. Many studies have used acidity alone to evaluate the survival of probiotic strains during the passage of the stomach. In our study, it seemed interesting to test our strains against the effect of low $\mathrm{pH}$ alone and with respect to simulated gastric conditions (low $\mathrm{pH}$ effects with pepsin). Effect of $\mathrm{pH} 1.5$, alone, on Lactobacillus spp. strains were examined after $1 \mathrm{~h}$ and $2 \mathrm{~h}$ exposure.

With respect to the assessment of the capacity of Lactobacillus spp. strains isolated to survive under conditions mimicking those of the human stomach, we prepared the simulated gastric juice by adding a solution of $0.5 \% \mathrm{NaCl}(\mathrm{W} / \mathrm{V})$ to a solution of pepsin concentration $3 \mathrm{~g} / \mathrm{l}$. The preparation was adjusted to $\mathrm{pH}$ 1.5. One milliliter of each bacterial culture was inoculated into $9 \mathrm{ml}$ of the simulated gastric juice. Then, $100 \mu 1$ of the seeded gastric juice was taken at $0 \mathrm{~h}$ and $2 \mathrm{~h}$ of exposure and inoculated by spreading on MRS agar. The number of colony-forming units (CFU) was determined after $48 \mathrm{~h}$ of anaerobic incubation. The experiment was repeated 3 times. The survival rate will be calculated by the following equation: Survival rate $(\%)=\log \mathrm{CFU}$ to $\mathrm{T}_{2 \mathrm{~h}} / \log \mathrm{CFU}$ to $\mathrm{T}_{0 \mathrm{~h}} \times 100$.

\section{Antibacterial activity}

The antibacterial activity of Lactobacillus spp. strains isolated was determined by agar overlay method, against three strains of Salmonella spp., multidrug-resistant, and virulent isolated from slaughter animals in Southern Benin and one reference strain of Salmonella Typhimurium ATCC 14028 (Table-1) [11]. These strains were obtained at the Research Unit in Applied Microbiology and Pharmacology of Natural Substances of the University of Abomey-Calavi, Benin [11].

The Lactobacillus strains isolated were spot inoculated, separately, onto the MRS agar plates, using a sub-culture $(20 \mu \mathrm{l} / \mathrm{spot})$ of MRS broth culture (grown at $37^{\circ} \mathrm{C}$ for $24 \mathrm{~h}$ ) of the Lactobacillus strains, and the inoculated plates were incubated at $37^{\circ} \mathrm{C}$ for $24 \mathrm{~h}$. The MRS agar plates containing the growth of Lactobacillus strains in spot form were thereafter overlaid with soft Mueller-Hinton agar (Biokar, French, BK048HA) pre-mixed with $100 \mu 1$ (McFarland 1) of Salmonella spp. strains and Salmonella Typhimurium ATCC 14028 and incubated, after solidification of the overlaid agar medium, at $37^{\circ} \mathrm{C}$ for $24 \mathrm{~h}$. The zone diameter of inhibition (ZDI) values obtained were measured and interpreted according to Halder et al. [12].

The "R" (width of clear zone) values were also determined as per the formula stated earlier [12]: $\mathrm{R}=(\mathrm{d}$ Inhib-d Spot $) / 2$; (d Inhib=the diameter of clear zone around the "d Spot;" and d Spot=the diameter of spot form of lactobacilli grown on MRS agar plate).

\section{Statistical analysis}

All tests were repeated thrice, and the data were represented as mean \pm standard deviation.

\section{Results}

\section{Physiological characters of isolates}

Of the 22 samples analyzed, 20 bacterial strains belonging to the genus Lactobacillus were isolated. The isolates were grown on selective MRS agar

Table-1: Characteristics of Salmonella spp. strains (indicator strains) used [11].

\begin{tabular}{lccccc}
\hline Strains & \multicolumn{4}{c}{ Virulence genes } \\
\cline { 2 - 5 } & invA & spvR & spvC & fimA & Stn \\
\hline P9 & + & + & & + & + \\
P14 & + & & & + & + \\
P19 & + & + & + & + & + \\
Salmonella Typhimurium & + & + & + & + & + \\
ATCC 14028 & & & & & \\
\hline
\end{tabular}

P9; P14; P19; P29 are identified Salmonella spp. strains; +=Presence, fimA=Fimbriae production factor, invA=Invasion factor, $S p v R$ and $S p v C=$ Systemic infection (inhibition activation of macrophage), $S t n=$ Enterotoxigenic substances production 
medium and gave a round or lenticular shape, whitish in color with regular outline (Figure-1a). After Gramstaining, we observed Gram-positive, short-medium, and sometimes diploid bacilli or coccobacilli (Figure-1b). The majority of isolates were able to grow in MRS broth at different temperatures except at the temperature of $15^{\circ} \mathrm{C}$. The cultivation of the strains in the presence of different concentrations of $\mathrm{NaCl} 6.5$ and $4 \%$, allowed us to evaluate their ability to grow in hostile conditions. The majority of identified strains have resisted the different concentrations of $\mathrm{NaCl}$ solution to which they are subjected. Nevertheless, Lactobacillus casei A3-1, Lactobacillus plantarum



Figure-1: (a) typical colony characteristics of the isolates grown on MRS agar medium; (b) Microscopic view of the isolates when Gram stained.

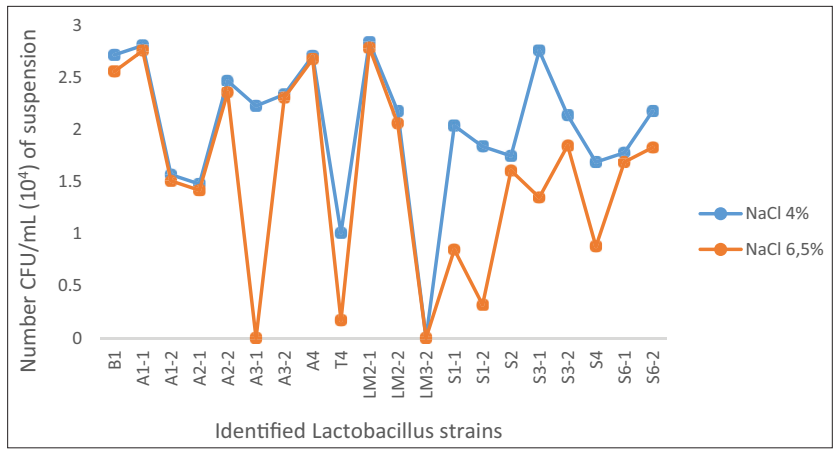

Figure-2: Tolerance of identified Lactobacillus strains with sodium chloride.
LM3-2, and Lactobacillus acidophilus T4 strains were unable to resist the $6.5 \% \mathrm{NaCl}$ solution (Figure-2).

\section{Biochemical characterization}

Catalase, oxidase, and indole tests performed as part of the biochemical characterization of the isolates gave negative results for all isolates. The distribution according to fermental type was unequal between strains. The homofermentative strains represent almost all the number of isolates. The determination of genera and bacterial species lies mainly in their ability to ferment sugars lactic acid and other organic acids. The analysis of the fermental profiles reveals a great metabolic diversity of the carbohydrates in the isolates. Carbohydrate utilization test was performed to investigate whether the isolates can ferment lactose, sucrose, glucose, maltose, galactose, fructose, arabinose, and mannitol (Table-2). Of the 20 strains identified, nine (45\%) were isolated from raw cow milk samples with a high proportion of $L$. casei (55.56\%) followed by L. plantarum (33.33\%). About $40 \%(8 / 20)$ of the strains identified came from infantile stool samples, with 50\% Lactobacillus delbrueckii and $37.50 \%$ Lactobacillus salivarius. About 15\% (3/20) of the strains identified came from breast milk samples with a high proportion of $L$. plantarum (66.67\%). After identification of the strains, the most represented species is L. plantarum (30\%), followed by L. delbrueckii (25\%), L. casei (25\%), L. salivarius (15\%), and L. acidophilus (05\%) (Table-3).

\section{Probiotic activity}

\section{Ability of Lactobacillus spp. isolates to survive in gastric conditions}

To exercise their probiotic power, the strains must be able to survive the gastric conditions in vivo. This is how the present study tested their survival in simulated gastric conditions in vitro. From Figure-3, it appears that $\mathrm{pH} 1.5$, alone, has a drastic effect

Table-2: Results of the biochemical tests carried out on isolates.

\begin{tabular}{|c|c|c|c|c|c|c|c|c|c|c|c|c|c|c|}
\hline \multirow{3}{*}{$\begin{array}{l}\text { Identified species } \\
\text { (Isolates code) }\end{array}$} & \multicolumn{14}{|c|}{ Parameters } \\
\hline & \multirow[t]{2}{*}{ Catalase } & \multirow[t]{2}{*}{ Oxidase } & \multirow[t]{2}{*}{ Indole } & \multirow{2}{*}{$\begin{array}{l}\text { Growth } \\
\text { at } 45^{\circ} \mathrm{C}\end{array}$} & \multicolumn{10}{|c|}{ Sugar fermentation } \\
\hline & & & & & Ara & Lac & Glu & Fru & Gal & Man & Mal & Suc & Raf & Rha \\
\hline $\begin{array}{l}\text { Lactobacillus salivarius } \\
(\mathrm{S} 6-1 ; \text { S6-2; S3-1) }\end{array}$ & - & - & - & + & - & + & $+*$ & + & + & + & + & + & + & + \\
\hline $\begin{array}{l}\text { Lactobacillus acidophilus } \\
\text { (T4) }\end{array}$ & - & - & - & + & - & + & $+*$ & + & + & - & + & + & - & - \\
\hline $\begin{array}{l}\text { Lactobacillus delbruekii } \\
\text { (S3-2; S2; S1-2; S1-1; } \\
\text { LM2-1) }\end{array}$ & - & - & - & + & - & + & $+*$ & + & + & - & + & + & + & - \\
\hline $\begin{array}{l}\text { Lactobacillus casei } \\
(A 1-2 ; A 2-2 ; A 3-1 ; A 4 ; B 1)\end{array}$ & - & - & - & + & - & + & $+^{*}$ & + & + & + & + & + & - & - \\
\hline $\begin{array}{l}\text { Lactobacillus plantarum } \\
\text { (S4; LM2-2; A3-2; A1-1; } \\
\text { A2-1; LM3-2) }\end{array}$ & - & - & - & + & + & + & $+*$ & + & + & + & + & + & + & + \\
\hline
\end{tabular}

Ara: Arabinose; Lac: Lactose; Glu: Glucose; Fru: Fructose; Gal: Galactose; Man: Mannitol; Mal: Maltose; Suc: Sucrose; Raf: Raffinose; Rha: Rhamnose; *No gas production from glucose 
on some of the identified strains. In fact, of the 20 Lactobacillus strains tested, 17 resisted after $1 \mathrm{~h}$ of incubation, and 16 showed remarkable resistance after $2 \mathrm{~h}$ of exposure. It thus appears that the sensitivity of Lactobacillus to the acidic $\mathrm{pH}$ depends on the strain since even the acid-fast strains have shown, differently, more or less interesting survival rates, ranging from $20 \%$ to $83 \%, 50 \%$ (Table- 4 ). Of the 16 strains resistant to $\mathrm{pH} 1.5$, only 14 resisted stimulated gastric conditions ( $\mathrm{pH} 1.5+$ pepsin). The strains of L. salivarius S6-1 and S6-2 were completely inhibited. The highest resistance rate was observed with $L$. salivarius S3-1 (60.76\%), followed by L. casei B1 (60\%), L. plantarum S4 (57.55\%), L. delbrueckii S2 (53\%), and L. delbrueckii S3-2 (52.58\%) (Table-4).

\section{Anti-Salmonella spp. activity of Lactobacillus spp.} isolates

The identified Lactobacillus strains showed excellent antibacterial activity against Salmonella spp.

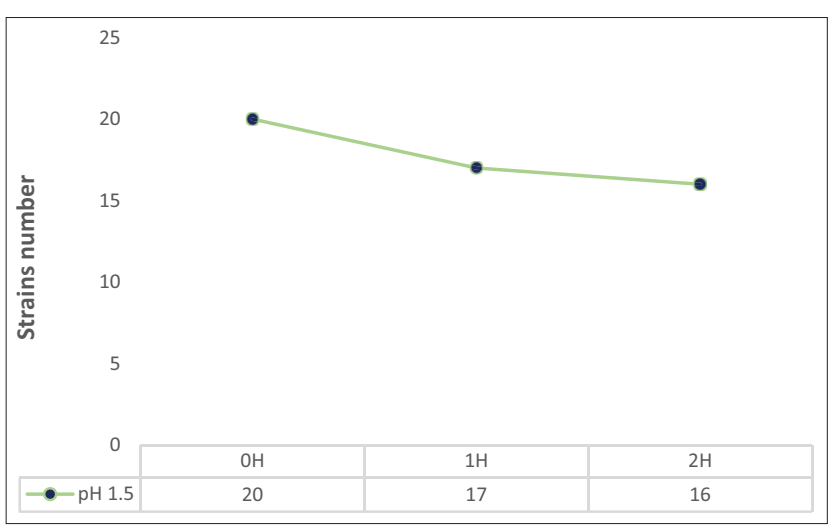

Figure-3: Effect of pH 1.5 on identified Lactobacillus.

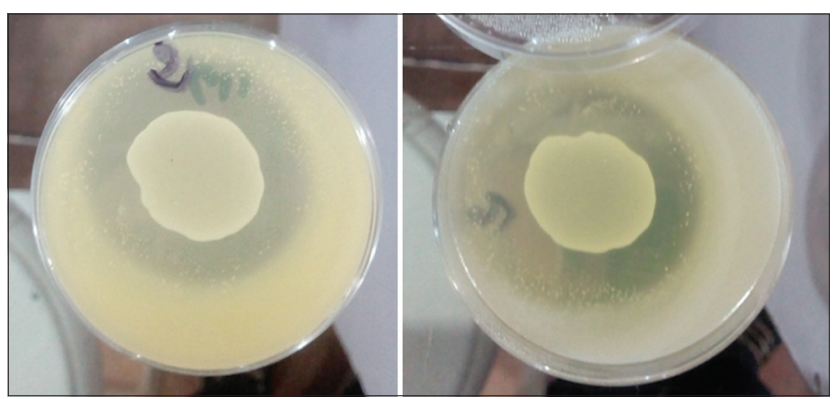

Figure-4: Antimicrobial Activity of isolated Lactobacillus spp. Clear zone indicates inhibition of bacterial growth. strains tested (Figure-4). The L. salivarius S3-1 strains had top growth inhibitory activity against three virulent and multidrug-resistant Salmonella spp. used and Salmonella Typhimurium ATCC 14028 with ZDI ranging from $30.75 \pm 0.06 \mathrm{~mm}$ to $35.33 \pm 0.05 \mathrm{~mm}$. The L. plantarum A1-1 and LM2-2 had poor antibacterial activity against indicator strains used with ZDI ranging from $12.36 \pm 0.03 \mathrm{~mm}$ to $16.25 \pm 0.23 \mathrm{~mm}$ (Table-5).

The " $R$ " values of identified Lactobacillus strains against Salmonella spp. strains used are represented in Table-6. L. plantarum A1-1 and LM2-2 have very low inhibition against Salmonella spp. strains and against Salmonella Typhimurium ATCC 14028 with R-values between $02.45 \pm 0.43 \mathrm{~mm}$ and $06.30 \pm 0.45$. On the other hand, all the other strains of Lactobacillus identified have strong inhibition against the same strains $(\mathrm{R}>6 \mathrm{~mm})$.

\section{Discussion}

The aim of this study was to evaluate the probiotic potential of some strains of Lactobacillus spp. to inhibit the in vitro the growth of virulent and multi-resistant strains of Salmonella spp. isolated from slaughter animals. To do this, it was a question of identifying strains of Lactobacillus spp. probiotic from breast milk, cow's milk, and infant stool samples and to assess their anti-Salmonella spp. activity. Isolation and purification of lactobacilli on the MRS agar medium led to the collection of 20 strains. Since lactobacilli are bacilli, microscopic examination of the isolates allowed us to observe $75 \%$ of bacilli and $25 \%$ of all Gram-positive coccobacilli. The results of the microscopic, macroscopic, and above all biochemical examination (fermentation of sugars) made it possible to identify several species, such as L. plantarum (30\%), L. delbrueckii (25\%), L. casei (25\%), L. salivarius $(15 \%)$, and L. acidophilus $(05 \%)$.

Probiotic strains, to be effective, must arrive alive to the site of their action, namely the intestine and therefore resist during their passage to the hostile conditions of the stomach such as acidity and the action of pepsin [13]. While sodium chloride inhibits the growth of many other types of bacteria, probiotic bacteria resist high levels of salt in the human gut [14]. The majority of Lactobacillus isolates were resistant to the various $\mathrm{NaCl}$ solution (4-6.5\%) except $L$. casei A3-1 and L. plantarum LM3-2, which could not withstand $\mathrm{NaCl} 6.5 \%$ solution. All L. casei strains are

Table-3: Distribution of identified Lactobacillus strains according to different types of samples.

\begin{tabular}{|c|c|c|c|c|c|c|}
\hline \multirow[t]{2}{*}{ Sample types } & \multicolumn{5}{|c|}{ Identified bacterial species } & \multirow[t]{2}{*}{ Total } \\
\hline & L. salivarius & L. acidophilus & L. delbrueckii & L. casei & L. plantarum & \\
\hline Infantile stool & $\begin{array}{c}3 \\
(37.50 \%)\end{array}$ & - & $\begin{array}{c}4 \\
(50 \%)\end{array}$ & - & $\begin{array}{c}1 \\
(12.50 \%)\end{array}$ & 8 \\
\hline Raw cow milk & - & $\begin{array}{c}1 \\
(11.11 \%)\end{array}$ & - & $\begin{array}{c}5 \\
(55.56 \%)\end{array}$ & $\begin{array}{c}3 \\
(33.33 \%)\end{array}$ & 9 \\
\hline Breast milk & - & - & $\begin{array}{c}1 \\
(33.33 \%)\end{array}$ & - & $\begin{array}{c}2 \\
(66.67 \%)\end{array}$ & 3 \\
\hline Total & $\begin{array}{c}3 \\
(15 \%)\end{array}$ & $\begin{array}{c}1 \\
(05 \%)\end{array}$ & $\begin{array}{c}5 \\
(25 \%)\end{array}$ & $\begin{array}{c}5 \\
(25 \%)\end{array}$ & $\begin{array}{c}6 \\
(30 \%)\end{array}$ & 20 \\
\hline
\end{tabular}


Table-4: Ability of lactobacilli strains to survive in simulated gastric conditions.

\begin{tabular}{|c|c|c|c|c|c|}
\hline \multirow{2}{*}{$\begin{array}{l}\text { Identified Lactobacillus } \\
\text { strains }\end{array}$} & \multirow[t]{2}{*}{ Codes } & \multicolumn{4}{|c|}{ Viable cultures number $\left(\log \mathrm{cfu} . \mathrm{mL}^{-1}\right) *$ at times $\mathrm{OH}$ and $2 \mathrm{H}$} \\
\hline & & Simulated gastric juice & Он & $\mathbf{2 H}$ & Survival rate (\%) \\
\hline \multirow[t]{6}{*}{ L. salivarius } & S3-1 & $\mathrm{pH} 1.5$ & $2.37 \pm 0.46$ & $1.81 \pm 0.01$ & 73.37 \\
\hline & & $\mathrm{pH} 1.5+$ pepsin & & $1.44 \pm 0.02$ & 60.76 \\
\hline & S6-1 & $\mathrm{pH} 1.5$ & $1.85 \pm 0.02$ & $0.42 \pm 0.03$ & 22.70 \\
\hline & & $\mathrm{pH} 1.5+$ pepsin & & 0 & 0 \\
\hline & $56-2$ & $\mathrm{pH} 1.5$ & $1.40 \pm 0.01$ & $0.28 \pm 0.02$ & 20 \\
\hline & & $\mathrm{pH} 1.5+$ pepsin & & 0 & 0 \\
\hline \multirow[t]{8}{*}{ L. delbrueckii } & $S 1-1$ & $\mathrm{pH} 1.5$ & $1.82 \pm 0.02$ & $1.22 \pm 0.03$ & 63.03 \\
\hline & & $\mathrm{pH} 1.5+$ pepsin & & $0.88 \pm 0.02$ & 48.35 \\
\hline & $S 2$ & $\mathrm{pH} 1.5$ & $2.34 \pm 0.03$ & $1.81 \pm 0.02$ & 77.35 \\
\hline & & $\mathrm{pH} 1.5$ + pepsin & & $1.24 \pm 0.02$ & 53 \\
\hline & S3-2 & $\mathrm{pH} 1.5$ & $1.94 \pm 0.04$ & 1.620 .01 & 83.50 \\
\hline & & $\mathrm{pH} 1.5+$ pepsin & & $1.02 \pm 0.04$ & 52.58 \\
\hline & LM2-1 & $\mathrm{pH} 1.5$ & $2.45 \pm 0.01$ & $0.90 \pm 0.02$ & 36.73 \\
\hline & & $\mathrm{pH} 1.5+$ pepsin & & $0.83 \pm 0.04$ & 33.88 \\
\hline \multirow[t]{8}{*}{ L. casei } & $A 1-2$ & $\mathrm{pH} 1.5$ & $2.31 \pm 0.02$ & $1.30 \pm 0.02$ & 56.28 \\
\hline & & $\mathrm{pH} 1.5+$ pepsin & & $0.95 \pm 0.02$ & 41.13 \\
\hline & $A 2-2$ & $\mathrm{pH} 1.5$ & $2.36 \pm 0.01$ & $1.65 \pm 0.01$ & 69.92 \\
\hline & & $\mathrm{pH} 1.5+$ pepsin & & $0.97 \pm 0.01$ & 41.10 \\
\hline & A4 & $\mathrm{pH} 1.5$ & $2.82 \pm 0.03$ & $0.98 \pm 0.02$ & 34.75 \\
\hline & & $\mathrm{pH} 1.5+$ pepsin & & $0.62 \pm 0.03$ & 21.99 \\
\hline & $B 1$ & pH 1.5 & $2.30 \pm 0.01$ & $1.73 \pm 0.02$ & 75.22 \\
\hline & & $\mathrm{pH} 1.5+$ pepsin & & $1.38 \pm 0.07$ & 60 \\
\hline \multirow[t]{10}{*}{ L. plantarum } & $A 1-1$ & $\mathrm{pH} 1.5$ & $2.48 \pm 0.01$ & $1.52 \pm 0.04$ & 61.29 \\
\hline & & $\mathrm{pH} 1.5+$ pepsin & & $1.05 \pm 0.02$ & 42.34 \\
\hline & $A 2-1$ & $\mathrm{pH} 1.5$ & $2.95 \pm 0.03$ & $1.77 \pm 0.02$ & 60 \\
\hline & & $\mathrm{pH} 1.5+$ pepsin & & $1.19 \pm 0.01$ & 40.34 \\
\hline & A3-2 & $\mathrm{pH} 1.5$ & $2.31 \pm 0.01$ & $1.70 \pm 0.02$ & 73.59 \\
\hline & & $\mathrm{pH} 1.5+$ pepsin & & $0.99 \pm 0.02$ & 42.86 \\
\hline & S4 & $\mathrm{pH} 1.5$ & $2.12 \pm 0.02$ & $1.70 \pm 0.01$ & 80.19 \\
\hline & & $\mathrm{pH} 1.5+$ pepsin & & $1.22 \pm 0.03$ & 57.55 \\
\hline & LM2-2 & $\mathrm{pH} 1.5$ & $1.71 \pm 0.01$ & $0.77 \pm 0.03$ & 45.03 \\
\hline & & $\mathrm{pH} 1.5+$ pepsin & & $0.42 \pm 0.03$ & 24.56 \\
\hline
\end{tabular}

(log cfu.mL-1)*: the values of log CFU.mL. ${ }^{-1}$ express mean \pm standard deviation, each data point is mean of repeated measurements of 3 experiments independent, $n=3 . p<0.05$.

isolated from cow milk samples (A1-2; A2-2; A3-1; A4; and B1), apart from the A3-1 strain, the others are resistant to $\mathrm{NaCl}(4-6.5 \%)$. These results are similar to those of Halder and Mandal [14] who showed that all $L$. casei strains isolated from curd samples are resistant to $\mathrm{NaCl}$ solution (4-6.5\%).

During fasting, the stomach $\mathrm{pH}$ can go down very low, up to 1.5 in some people, which can fatally affect bacterial growth [15]. In our study, Lactobacillus isolates showed very different behaviors with respect to their sensitivity to $\mathrm{pH} 1.5$. This had a drastic effect on four identified strains of Lactobacillus (L. acidophilus T4, L. delbrueckii S1-2, L. casei A3-1, and L. plantarum LM3-2) but 16 strains resisted this strong acidity after $2 \mathrm{~h}$ of incubation. It was demonstrated that for probiotic characterization of lactobacilli, acid tolerance is an important criterion, and the $\mathrm{pH}$ value of 3.0 has been considered standard for such investigation of probiotic strains [3]. Thus, the 16 strains resistant to $\mathrm{pH} 1.5$ are potential probiotic strains. However, it can be seen that $\mathrm{pH}$ alone is not a good criterion for evaluating the resistance of probiotic strains during their passage through the stomach. Two of the 16 strains resistant to $\mathrm{pH} 1.5$ could not withstand the simulated gastric conditions ( $\mathrm{pH} 1.5+$ pepsin). These are
L. salivarius strains S6-1 and S6-2. Strains resistant to simulated gastric juice: L. salivarius S3-1, L. delbrueckii (S1-1, S2, S3-2, and LM2-1), L. casei (A1-2, A2-2, $\mathrm{A} 4$, and $\mathrm{B} 1$ ), and L. plantarum (A1-1, A2-1, A3-2, S4, and LM2-2) showed more or less interesting and variable survival rates from one strain to another. With regard to the best survival rate of isolates under-stimulated gastric conditions, L. delbrueckii S3-2 and L. plantarum S4 lead with, respectively, $83.50 \%$ and $80.19 \%$ (Table-4). These results are similar to those obtained by Sirichokchatchawan et al. [16], which showed that $L$. plantarum isolated from pig feces was higher tolerance to stimulated gastric conditions with a survival rate of $90.71 \%$.

Antagonist activity is one of the functional requirements of probiotics. In this study, virulent and multi-resistant Salmonella spp. strains were selected as indicator bacteria. The Lactobacillus strains studied showed different anti-Salmonella spp. activities. The most active strains are $L$. salivarius $\mathrm{S} 3-1$, L. delbrueckii S1-1, L. casei $\mathrm{A} 4$ and $\mathrm{B} 1$, and L. plantarum A3-2 with ZDIs of $28.22 \pm 0.03 \mathrm{~mm}-35.33 \pm 0.05 \mathrm{~mm}$ (Table-5). These results are similar to those obtained by Sirichokchatchawan et al. [16], where strains of L. plantarum isolated from pig feces have a strong 
Available at www.veterinaryworld.org/Vol.12/December-2019/10.pdf

Table-5: Antibacterial activity of the identified Lactobacillus strains, in terms of ZDI.

\begin{tabular}{|c|c|c|c|c|c|}
\hline \multirow{2}{*}{$\begin{array}{l}\text { Identified } \\
\text { Lactobacillus } \\
\text { strains }\end{array}$} & \multirow[t]{2}{*}{ Codes } & \multicolumn{4}{|c|}{ ZDI $(\mathrm{mm})$, Mean \pm SD for indicator strains } \\
\hline & & P9 & P14 & P19 & $\begin{array}{c}\text { Salmonella Typhimurium } \\
\text { ATCC } 14028\end{array}$ \\
\hline L. salivarius & S3-1 & $35.33 \pm 0.05$ & $33.37 \pm 0.46$ & $30.81 \pm 0.01$ & $34.23 \pm 0.52$ \\
\hline \multirow[t]{4}{*}{ L. delbrueckii } & $S 1-1$ & $31.52 \pm 0.24$ & $30.82 \pm 0.02$ & $28.22 \pm 0.03$ & $29.42 \pm 0.35$ \\
\hline & 52 & $29.25 \pm 0.45$ & $27.34 \pm 0.03$ & $27.31 \pm 0.02$ & $25.84 \pm 0.64$ \\
\hline & S3-2 & $23.62 \pm 0.35$ & $21.94 \pm 0.04$ & $21.62 \pm 0.01$ & $22.41 \pm 0.01$ \\
\hline & LM2-1 & $26.16 \pm 0.02$ & $26.45 \pm 0.01$ & $23.90 \pm 0.02$ & $25.13 \pm 0.54$ \\
\hline \multirow[t]{4}{*}{ L. casei } & $A 1-2$ & $18.56 \pm 1.05$ & $17.31 \pm 0.02$ & $16.3 \pm 01.25$ & $16.38 \pm 0.52$ \\
\hline & $A 2-2$ & $28.50 \pm 0.01$ & $24.36 \pm 0.01$ & $27.65 \pm 00.01$ & $26.25 \pm 0.24$ \\
\hline & A4 & $33.43 \pm 0.54$ & $32.82 \pm 0.03$ & $34.98 \pm 00.02$ & $34.28 \pm 0.04$ \\
\hline & $B 1$ & $33.84 \pm 0.63$ & $34.30 \pm 0.01$ & $31.38 \pm 00.07$ & $30.75 \pm 0.06$ \\
\hline \multirow[t]{5}{*}{ L. plantarum } & $A 1-1$ & $14.65 \pm 0.58$ & $12.48 \pm 0.01$ & $13.52 \pm 00.04$ & $12.36 \pm 0.03$ \\
\hline & $A 2-1$ & $24.65 \pm 0.35$ & $21.95 \pm 0.03$ & $21.77 \pm 0.02$ & $20.64 \pm 0.03$ \\
\hline & A3-2 & $31.25 \pm 0.02$ & $30.31 \pm 0.01$ & $30.70 \pm 00.02$ & $31.54 \pm 0.04$ \\
\hline & S4 & $28.65 \pm 0.56$ & $26.12 \pm 0.02$ & $26.70 \pm 00.01$ & $26.84 \pm 0.05$ \\
\hline & LM2-2 & $16.25 \pm 0.23$ & $15.71 \pm 0.01$ & $15.77 \pm 00.03$ & $14.95 \pm 0.02$ \\
\hline
\end{tabular}

Table-6: The « $R$ » values of identified Lactobacillus strains against the indicator strains used.

\begin{tabular}{|c|c|c|c|c|c|}
\hline \multirow{2}{*}{$\begin{array}{l}\text { Identified } \\
\text { Lactobacillus } \\
\text { strains }\end{array}$} & \multirow[t]{2}{*}{ Codes } & \multicolumn{4}{|c|}{ R Value $(\mathbf{m m})$, Mean $\pm S D$, for indicator strains } \\
\hline & & P9 & P14 & P19 & $\begin{array}{c}\text { Salmonella Typhimurium } \\
\text { ATCC } 14028\end{array}$ \\
\hline L. salivarius & S3-1 & $16.05 \pm 0.29$ & $15.37 \pm 0.35$ & $13.75 \pm 0.51$ & $15.67 \pm 0.41$ \\
\hline \multirow[t]{4}{*}{ L. delbrueckii } & $S 1-1$ & $14.33 \pm 0.29$ & $13.62 \pm 0.01$ & $13.08 \pm 0.23$ & $13.46 \pm 0.29$ \\
\hline & S2 & $13.35 \pm 0.35$ & $12.67 \pm 0.65$ & $12.41 \pm 0.01$ & $10.75 \pm 0.46$ \\
\hline & S3-2 & $10.23 \pm 0.35$ & $09.54 \pm 0.02$ & $05.14 \pm 0.21$ & $10.04 \pm 0.31$ \\
\hline & $L M 2-1$ & $11.05 \pm 0.22$ & $11.35 \pm 0.02$ & $10.36 \pm 0.52$ & $10.85 \pm 0.51$ \\
\hline \multirow[t]{4}{*}{ L. casei } & $A 1-2$ & $08.64 \pm 0.05$ & $07.25 \pm 0.62$ & $06.45 \pm 1.25$ & $06.68 \pm 0.54$ \\
\hline & $A 2-2$ & $13.10 \pm 0.01$ & $10.50 \pm 0.01$ & $12.65 \pm 0.02$ & $11.25 \pm 0.34$ \\
\hline & A4 & $15.33 \pm 0.51$ & $14.62 \pm 0.01$ & $15.84 \pm 0.25$ & $15.68 \pm 0.34$ \\
\hline & $B 1$ & $15.54 \pm 0.02$ & $15.50 \pm 0.03$ & $14.08 \pm 0.05$ & $13.49 \pm 0.51$ \\
\hline \multirow[t]{5}{*}{ L. plantarum } & $A 1-1$ & $04.52 \pm 0.48$ & $02.54 \pm 0.06$ & $03.52 \pm 0.25$ & $02.45 \pm 0.43$ \\
\hline & $A 2-1$ & $10.50 \pm 0.45$ & $09.85 \pm 0.01$ & $09.67 \pm 0.01$ & $09.15 \pm 0.53$ \\
\hline & A3-2 & $14.35 \pm 0.52$ & $13.65 \pm 0.51$ & $13.72 \pm 0.32$ & $14.25 \pm 0.45$ \\
\hline & S4 & $13.10 \pm 0.51$ & $11.25 \pm 0.42$ & $11.85 \pm 0.21$ & $11.94 \pm 0.04$ \\
\hline & LM2-2 & $06.30 \pm 0.45$ & $05.61 \pm 0.04$ & $05.87 \pm 0.05$ & $04.79 \pm 0.42$ \\
\hline
\end{tabular}

antibacterial activity on Salmonella Typhimurium ATCC 13311 and Salmonella choleraesuis with ZDIs $>17 \mathrm{~mm}$. Likewise, our results are similar to those of Adetoye et al. [3] and Halder et al. [12]. Adetoye et al. [3] showed that two L. plantarum strains and one $L$. salivarius strain isolated from cattle feces had a strong antibacterial activity on Salmonella enterica strains with, respectively, ZDIs of 12-18 and $>18 \mathrm{~mm}$. As for Halder et al. [12], they showed that L. plantarum strain isolated from curd samples had a strong antibacterial activity on Salmonella Typhi of human origin $(\mathrm{ZDI}=25.25 \pm 1.71 \mathrm{~mm})$. Our results are better than those obtained by Yamazaki et al. [17], where strains of $L$. delbrueckii, $L$. plantarum, $L$. casei, and L. salivarius isolated from chicken feces had low anti-Salmonella spp. activity with ZDIs ranging from $1.3 \pm 0.4 \mathrm{~mm}$ to $11.7 \pm 1.0 \mathrm{~mm}$. According to Halder et al. [12], when " $\mathrm{R}$ " was $<2 \mathrm{~mm}$ that the scores of growth inhibition of indicator bacteria were considered as no inhibition capacity; low inhibition capacity with " $R$ " values of $2-5 \mathrm{~mm}$, and high inhibition capacity with " $R$ " values $>6 \mathrm{~mm}$. It should be noted that all selected strains of Lactobacillus have a strong inhibition $(\mathrm{R}>6 \mathrm{~mm})$ on virulent strains of Salmonella spp.

\section{Conclusion}

Lactobacillus strains isolated from cow milk, breast milk, and infantile stool might be used as valid candidates of probiotics and good alternatives for antibiotics in the fight against animal and human salmonellosis. To the best of our understanding, this is the first study unfolding the antagonistic activity of 14 Lactobacillus strains against pathogenic bacteria in Benin, and the probiotic potential of such lactic acid bacteria has been authenticated. However, further studies are required to explore the effectiveness of the antibacterial essence of such native lactobacilli, to be used as the alternative therapeutics, in combating bacterial antibiotic resistance and treating the infections.

\section{Authors' Contributions}

AJA and TVD wrote the protocol. AJA, TVD, $\mathrm{RB}$, and ED processed the samples and laboratory analysis. AJA did data processing and statistical analysis. AJA and RB wrote the manuscript. TVD and 
LB reviewed the manuscript. All authors read and approved the final manuscript.

\section{Acknowledgments}

This study was partly supported by the Research Unit in Applied Microbiology and Pharmacology of natural substances, Abomey-Calavi, Benin. The Research Unit provided bench space to conduct the research. The authors did not receive any funding for this study.

\section{Competing Interests} interests.

The authors declare that they have no competing

\section{Publisher's Note}

Veterinary World remains neutral with regard to jurisdictional claims in published institutional affiliation.

\section{References}

1. Abhisingha, M., Dumnil, J. and Pitaksutheepong, C. (2018) Selection of potential probiotic Lactobacillus with inhibitory activity against Salmonella and fecal coliform bacteria. Probiotics Antimicrob. Proteins, 10(2): 218-227.

2. Hung, Y.T., Lay, C.J., Wang, C.L. and Koo, M. (2017) Characteristics of non-typhoidal gastroenteritis in Taiwanese children: A 9year period retrospective medical record review. J. Infect. Public Health, 10(5): 518-521.

3. Adetoye, A., Pinloche, E., Adeniyi, B.A. and Ayeni, F.A. (2018) Characterization and anti-salmonella activities of lactic acid bacteria isolated from cattle feces. $B M C$ Microbiol., 18(96): 96.

4. Dougnon, T.V., Deguenon, E., Fah, L., Legba, B., Hounmanou, Y.M., Agbankpe, A.J., Amadou, A., Koudokpon, H., Fabiyi, K., Aniambossou, A., Assogba, P., Hounsa, E., de Souza, M., Avlessi, F., Dougnon, T.J., Gbaguidi, F., Boko, M., Bankolé, H.S. and Baba-Moussa, L. (2017) Traditional treatment of human and animal salmonellosis in Southern Benin: Knowledge of farmers and traditherapists. Vet. World, 10(6): 580-592.

5. Das, J.K., Mishra, D., Ray, P., Tripathy, P., Beuria, T.K., Singh, N. and Suar, M. (2013) In vitro evaluation of anti-infective activity of a Lactobacillus plantarum strain against Salmonella enterica serovar Enteritidis. Gut Pathog., 5(1): 11-13.
6. Dibong, S.D., Mpondo, E.M., Ngoye, A., Kwin, M.F. and Betti, J.L. (2011) Ethnobotanique et phytomédecine des plantes médicinales de Douala. J. Appl. Biosci., 37: 2496-2507.

7. Potočnjak, M., Pušić, P., Frece, J., Abram, M., Janković, T. and Gobin, I. (2017) Three new Lactobacillus plantarum strains in the probiotic toolbox against gut pathogen Salmonella enterica serotype Typhimurium. Food Technol. Biotechnol., 55(1): 48-54.

8. Liu, J., Gu, Z., Song, F., Zhang, H., Zhao, J. and Chen, W., (2019) Lactobacillus plantarum ZS2058 and Lactobacillus rhamnosus GG use different mechanisms to prevent Salmonella infection in vivo. Front. Microbiol., 10(299): 1-9.

9. Stiles, M.E. and Holzapfel, W.H. (1997) Review article lactic acid bacteria of foods and current taxonomy. Int. J. Microbiol., 36(1): 1-19.

10. Huang, Y. and Adams, M.C. (2004) In vitro assessment of the upper gastrointestinal tolerance of potential probiotic dairy propionibacteria. Int. J. Food Microbiol., 91(3): 253-260.

11. Deguenon, E., Dougnon, V., Lozes, E., Maman, N., Agbankpe, J., Abdel-Massih, R., Djegui, F., Baba-Moussa, L. and Dougnon, J. (2019) Resistance and virulence determinants of fecal Salmonella spp. isolated from slaughter animals in Benin. BMC Res. Notes, 12(1): 317.

12. Halder, D., Mandal, M., Sekhar, S., Kumar, N. and Mandal, S. (2017) Indigenous probiotic Lactobacillus isolates presenting antibiotic like activity against human pathogenic bacteria. Biomedicines, 5(2): 31 .

13. Dunne, C., O'Mahony, L., Murphy, L., Thornton, G., Morrissey, D., O'Halloran, S., Feeney, M., Flynn, S., Fitzgerald, G., Daly, C., Kiely, B., O'Sullivan, G.C., Shanahan, F. and Collins, J.K. (2001) In vitro selection criteria for probiotic bacteria of human origin: Correlation with in vivo findings. Am. J. Clin. Nutr., 73(2): 386S-392S.

14. Halder, D. and Mandal, S. (2015) Curd lactobacilli with probiotic potentiality. Transl. Biomed., 6(2): 1-6

15. Draser, B.S., Shiner, M. and McLeod, G.M. (1969) Studies on the intestinal flora. I. The bacterial flora of the gastrointestinal tract in healthy and achlorhydric persons. Gastroenterology, 56(1): 71-79.

16. Sirichokchatchawan, W., Pupa, P., Praechansri, P., Am-In, N., Tanasupawat, S., Sonthayanon, P. and Prapasarakul, N. (2018) Autochthonous lactic acid bacteria isolated from pig feces in Thailand show probiotic properties and antibacterial activity against enteric pathogenic bacteria. Microb. Pathog., 119(2018): 208-215.

17. Yamazaki, M., Ohtsu, H., Yakabe, Y., Kishima, M. and Abe, H. (2012) In vitro screening of lactobacilli isolated from chicken excreta to control Salmonella Enteritidis and Typhimurium. Br. Poult. Sci., 53(2): 183-189. 